\title{
A Note on Alleged PRO-Government
}

\author{
Joef Bayer
}

\section{The Chomsky/Aoun/Sportiche Theory of Government}

Chomsky (1981) proposes a definition of government which modifies a proposal that was later published in Aoun and Sportiche (1983). The definition by Aoun and Sportiche, as quoted by Chomsky (1981), is as follows:

\section{(1) The Aoun/Sportiche definition of government LGB, (6), p.164}

$\alpha$ governs $y$ in $[\beta \ldots . . . . \alpha \ldots . . .$.

(i) $\alpha=X^{\circ}$

(ii) where $\emptyset$ is a minimal projection, $\emptyset$ dominates $\propto$ if and only if $\emptyset$ dominates

With the help of this definition, the following data can be reduced to the so-called PRO-theorem, which requires that PRO must not be governed.

(2)a. I like reading books

b. I like his reading books

(3)a. * I like book

b. I like his book

PRO is an option for NP* in (2a), because the head of VP is in a different maximal projection than the virtual governee NP*, and XP is likely to be a maximal projection $\left(S^{\prime}\right)$ into which the verb like cannot govern. PRO is not an option, however, in (3a), because here NP* being in one and the same maximal projection as the $\mathrm{N}$-head book will be governed by this category. 
Notice that the definition in (1) does not involve the notion 'c-command'. In his revision of (1), Chomsky re-introduces this notion.

\section{(4) Chomsky's definition of government (LGB, (11), p.165)}

$$
\begin{aligned}
& \alpha \text { governs } y \text { in }\left[\beta \ldots . . . . \alpha_{\ldots} \ldots . . . .\right] \text {, where } \\
& \text { (i) } \mathrm{a}=\mathrm{X}^{\circ} \\
& \text { (ii) where } \emptyset \text { is a maximal projection, if } \emptyset \text { dominates, } \\
& \text { then } \varnothing \text { dominates } \alpha \\
& \text { (iii) a c-commands } y
\end{aligned}
$$

\section{C-Command is defined as follows:}

\section{(5) Chomsky's definition of c-command (LGB, (12), p.166)}

$\alpha$ c-commands $\beta$ if and only if

(i) or does not $\operatorname{contain} \beta$

(ii) Suppose that $\gamma_{1}, \ldots, \gamma_{n}$ is the maximal sequence such that

$$
\begin{aligned}
& \text { (a) } \gamma_{n}=\alpha \\
& \text { (b) } Y_{i}=\alpha j \\
& \text { (c) } Y_{i} \text { immediately dominates } y_{i+1} \\
& \text { Then if } ₫ \text { dominates } \alpha \text {, then either }(I) d \text { dominates } \beta \text {, } \\
& \text { or (II) } ₫=\gamma_{j} \text { and } \gamma_{1} \text { dominates } \beta \text {. }
\end{aligned}
$$

In (5) $n$ refers to $X^{\circ}, i$ to an intermediate bar-level and 1 to $X^{\max }$. What the definition then says is that $\beta$ will be c-commanded by $\alpha$ as long as a (maximal) category can be found upwards which dominates both. Thus, a lexical $\mathrm{X}^{\circ}$ category inside XP can still be a governor of something that lies outside XP. ${ }^{1}$ Chomsky uses this effect in order to explain the ungrammaticality of (6).

\section{(6) They gave me a vase broken}

The intended structure involves a small clause (SC) adjoined to the NP with a PRO-subject and an AP-predicate.
(7)

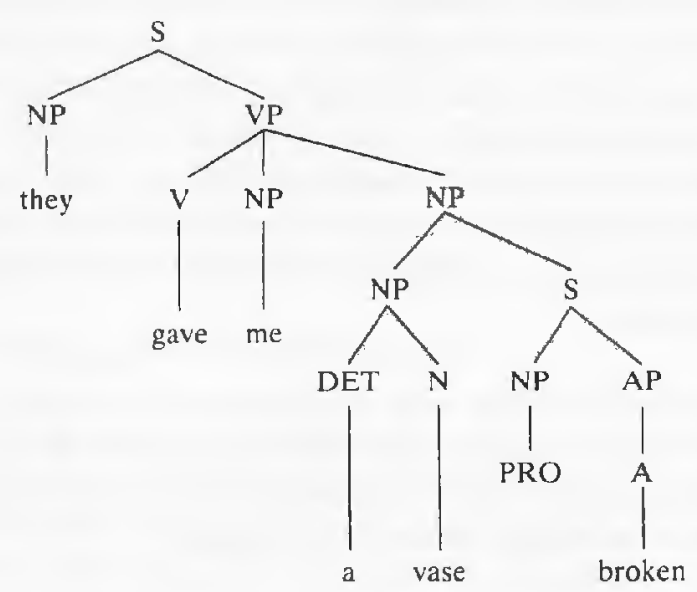

According to (5),(ii),(I), đ may be the adjoined node NP which also dominates PRO. (4) then enables vase to count as a governor of PRO. This violates the PRO-theorem, and thus an explanation of the ungrammaticality of (6) is found.

Chomsky, of course, mentions a number of comparable grammatical cases for which he has to find a solution as well. These cases are given in (8). ${ }^{2}$

\section{(8)a. They gave me something broken}

b. They gave me something broken into small pieces

c. They gave me a vase broken into small pieces

d. They gave me a vase that was broken into small pieces

e. I want the vase broken

Following early work by E. Williams, Chomsky proposes small clauses to be of category $S^{\prime}$ with $S^{\prime}$-deletion as the unmarked case. In the light of more recent developments this particular analysis appears to be outdated, but it will become clear that the thrust of Chomsky's proposal carries over to other analyses as well. Let us discuss ( $8 \mathrm{a}-\mathrm{c}$ ) successively: (8a) is argued to have the structure ... [something[PRO broken]]. In order to prevent this structure from being ruled out by the PRO-theorem, it is stipulated that something is not a lexical governor, thus leaving PRO ungoverned. The same argument would apply to (8b). 
For (8c), however, another device has to be invoked; broken into small pieces is a 'long' AP as compared with broken. It is then suggested that S'-deletion may not apply to 'long' APs, and that as a result the underlying PRO in (8c) may be successfully protected by an S'. In (8d), of course, there is no PRO, and the relative clause is an $S^{\prime}$, as overtly signalled by the presence of a complementizer. Finally, (8c) is said to be grammatical because want requires S'-deletion. Therefore, a phonetically realized NP has to appear as the deep-subject of broken.

Chomsky expresses uncertainty about the correctness of this analysis. I want to show in the remainder of this article that this analysis must be rejected and that the ill-formedness of (6) has nothing to do with a violation of the PRO-theorem. Let us first turn to the counter examples.

\section{A Dilemma ${ }^{3}$}

Notice that a minimal variation renders (6) grammatical.

(9) They gave me the vase broken

In (9), the definite article is used instead of the indefinite $a$. We can assume that the phrase structure of (9) would be the same as the one given under (7). Any attempt of making the government condition dependent on the nature of the specifier of the suspected governor seems to be extremely undesirable and should be rejected for principled reasons.

Another reason why the suggested analysis cannot be on the right track is this: Given that (8c) is grammatical, it should be expected that it remains grammatical under the substitution of arbitrary lexical NPs. This is, however, not the case. (10a) shows that - under at least one reading of the sentence -the substitution of an indefinite NP leads to a considerable deterioration, while $(10 \mathrm{~b})$ is not affected by this.

(10)a. I want a vase broken

b. I want a vase broken into small pieces
(I will turn to another reading of (10a) in section 2, and show that (10a) can be well-formed under this alternative reading). A further problem with the want-construction is that want must also be allowed to retain the S'-complement. Otherwise, we would lose an explanation for sentences with obligatory control like I want [PRO to go away from here]. Under Chomsky's assumption of a non-application of S'-deletion in long-AP SCs it remains unclear why there are no grammatical examples like

\section{(11) * I want [[PRO [AP broken into small pieces]]]}

Before I come to the score of my argument, let me indicate that the structure proposed in (7) may not be the correct one. German allows for predicative APs like English, but it also allows the intervention of adverbials between NP and AP which can otherwise not appear in complex NPs. An example is Sie gaben mir Vasen [die meiste Zeit] zerbrochen. 'they gave me vases most of the time broken'. As suggested by the occurrence of the bracketed phrase, Vasen cannot form a constituent together with zerbrochen. If this state of affairs holds for English too, the small clause should be adjoined to VP. Under any reasonable interpretation of (4) and (5) vase should then fail to govern PRO anyway. In the next section I will argue that an explanation of the ill-formedness of (6) and (10a) has to be sought in prosodic phonology rather than in syntax.

\section{Clashing Accents}

One of the most discussed issues in modern phonology is the interplay of stress-building rules and rules which convert the outcome of these rules into an optimal metrical grid. Chomsky and Halle (1968) (SPE) invoke post-cyclic word level rules ('Auxiliary Reduction') in order to get rid of stresses 'that are promoted in the cyclic application of the stress rules. Thus, a word like [[[component]ial]ity] could not lose the stress on $/ 0 /$, if no special rule is applied which destresses this segment. In this example, the rule would -- using the familiar SPE-numbering -- convert

$$
\begin{array}{llllllll}
2 & 3 & 2 & 1 & 3 & 3 & 1
\end{array}
$$

componentiality to componentiality. 
Liberman and Prince (1977) develop a metrical theory which defines stress not on an individual segment, but rather as relative prominence between prosodic constituents. Following an earlier formalization in Kiparsky (1966), they propose a mechanism which shifts a stress $X$ to the left, if the segment bearing $X$ is adjacent or 'too close' to a segment which bears a comparably heavy or heavier stress Y. This mechanism has become known as the 'Rhythm Rule' (RR). Since the appearance of these earlier discussions, rhythmic reorganization has been a major inspiration for the development of prosodic phonology. Important land marks in this development are Prince (1983), Hayes (1984), Selkirk (1984), Halle and Vergnaud (1987) and others. This is neither the place to review any of these nor to turn to the discussion whether grids are sufficient to represent stress -a view defended by Prince (1983) and Selkirk (1984) -- whether metrical trees alone are sufficient (Kiparsky, 1979) or whether a combination of metrical stress and the grid is necessary (Hayes, 1984). With the exception of Selkirk (1984), most of this work concentrates almost exclusively on the lexical domain, i.e., on underived and derived words including compounds. As far as the phrasal level is concerned, only short phrases are considered. The tendency in much of this work is to de-emphasize the role which syntax played in SPE-type stress rules and to emphasize the autonomy of the metrical structure underlying natural languages. ${ }^{4}$ Here we will mainly follow Selkirk (1984) in that her work represents the most explicit theory about the syntax phonology interface.

Selkirk -- following Liberman (1975) and subsequent work -- draws attention to the fact that in quasi minimal pairs like (12) and (13)

\section{(12)a. Marcel Proust \\ b. UB's library \\ (13)a. UB library}

b. Marcel proved

the Rhythm Rule (RR) is likely to affect (12/13a) but unlikely or less likely to affect $(12 / 13 \mathrm{~b})$. The reason for this is provided by rules of syntactic timing which insert more silent demibeats into the grid in phrases than in word structure. Selkirk proposes the following rules.

\section{(14) Silent Demibeat Addition (SDA)}

Add a silent demibeat at the right end (right extreme) of the metrical grid aligned with

a. a word

b. a word that is the head of a nonadjunct constituent

c. a phrase

d. a daughter phrase of $S^{5}$

Given the respective grids for the examples in (12) and (13), which are induced by lexical structure and by the Nuclear Stress Rule (NSR), one can derive the representation in (15) and (16) respectively. ${ }^{6}$ (15)a.

$\begin{array}{cccc} & & & \mathbf{x} \\ & \mathbf{x} & -- & \mathbf{x} \\ \mathbf{x} & \mathbf{x} & & \mathbf{x} \\ \mathbf{x} & \mathbf{x} & x & \mathbf{x} \\ \text { Marcel } & & \text { Proust }\end{array}$

(16)a.

$\begin{array}{lll} & & \mathrm{x} \\ \mathrm{x} & - & \mathrm{x} \\ \mathrm{xx} & & \mathrm{x} \quad \mathrm{x} \\ \mathrm{xx} & \mathrm{x} & \mathrm{x} \quad \mathrm{x} \mathbf{x} \\ \text { UB } & & \text { library }\end{array}$

b.

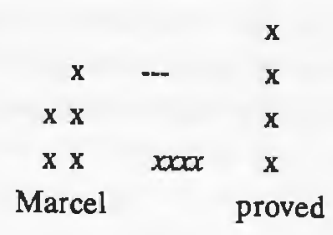

b.

$\begin{array}{lccc} & & \mathbf{x} & \\ \mathbf{x} & -- & \mathrm{x} & \\ \mathbf{x x} & & \mathrm{x} \quad \mathrm{x} \\ \mathbf{x x} & \mathbf{x x x} & \mathrm{x} \quad \mathrm{x} \quad \mathrm{x} \\ \text { UB's } & & \text { library }\end{array}$

The RR can now be thought to apply in the (a)-examples where there is little distance between the main beats, which clash on the third grid level, but there is no necessity for it to apply in the (b)-examples, because the main beats are sufficiently separated by the intervening silent beats. ${ }^{7}$ Thus only the (a)-examples are likely to be changed by the RR. 8

As Wiese (1986) in his review of Selkirk (1984) remarks, rules like those in (14) reintroduce a considerable amount of syntax, ultimately the boundary symbols of SPE-phonology. An alternative could be that the RR can act only in certain 
environments among which lexical structures and syntactic [modifier thead] constructions, but not in, say, predication. ${ }^{9}$ In our following account for the sentences in (6) through (10), we will not make explicit assumptions about the domain in which the RR would become active. What the examples in (15) and (16) in conjunction with Selkirk's account show, however, is the fact that

(a) clashing accents are disfavored and that

(b) clashes may be avoided by an application of the RR or other rules of grid readjustment, or by the syntactic separation of the clashing accent.

\section{The Accentuation of Small Clause}

Broken in sentence (9), They gave me the vase broken, is clearly an adjunct phrase. We do not assume the vase to be its SUBJECT, but -- following Stowell (1983) -- PRO, which is then coindexed with the vase. ${ }^{10}$ For reasons which will become clear as we proceed, the SC should not be adjoined to the NP, but rather to the V-projection, here VP. The following representation shows the hypothesized syntactic structure in the lower dimension and the grid structure, as built by the NSR, in the upper dimension.

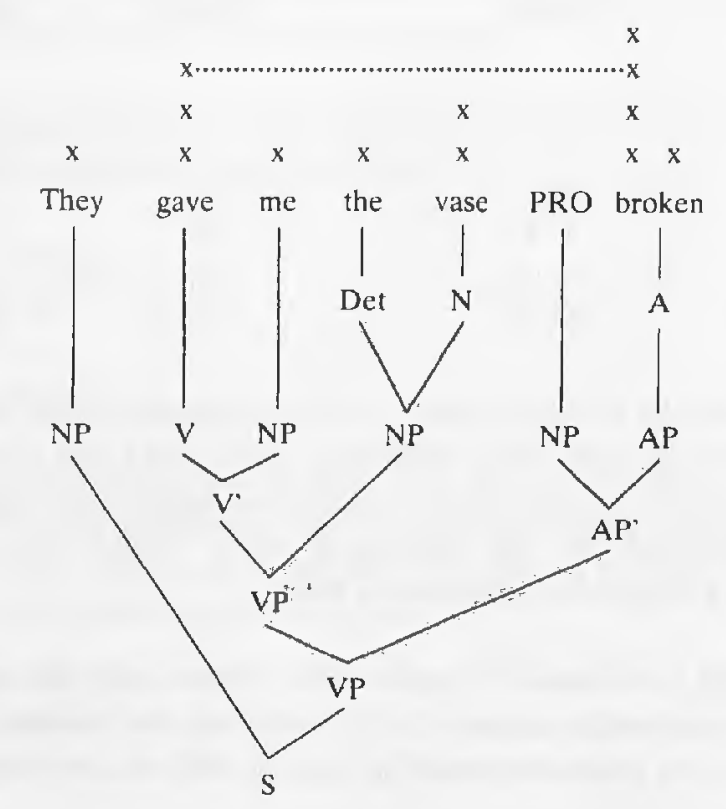

Rules of grid-euphony are responsible for the retraction of ternary stress from vase and shifting it to the left on gave. This leaves us with an optimal distance between the main stresses. 11

We now turn to the ill-formed example (6), "They gave me a vase broken, which we assume has the same syntactic structure as (17) above. Therefore, only the metrical structure will be given.

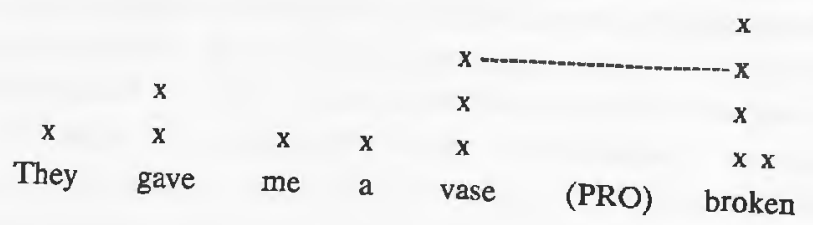

Under the proposed syntactic analysis the/a vase is the direct object of gave. The indefinite NP a vase introduces new information. Two assumptions about items which carry new information can safely be made: The first is that they must be phonologically prominent; the second is that this marking of prominence cannot be shifted elsewhere. ${ }^{12}$ To the extent that phonological prominence involves at least a third level in the grid, the accent on vase will clash with the accent on broken which is induced by the NSR. This explains the ill-formedness of $(6) /(18)$.

It is quite clear how the well-formedness of the examples in (8) follows. Whatever the structure of (8a) They gave me something broken is, something being a function word will not bear stress above grid level two unless it is into small piecessed. The same holds for (8b), They gave me something broken stress a tike (8b), (8c) involves a long AP which means in terms of stress assignment that the NSR places the main stress on the rightmost (stressable) head. This leads to the following structure.

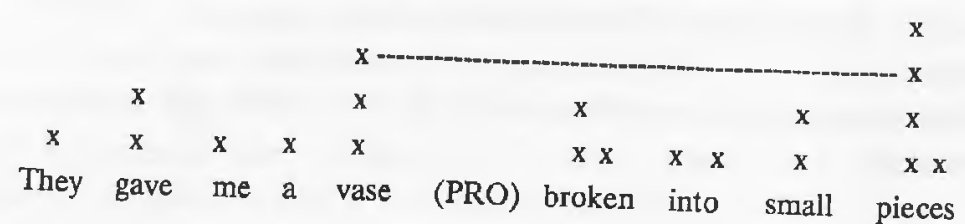


At grid level three the main stresses are more than well separated. The same holds, of course, for (8d) They gave me a vase that was broken into small pieces, where seven unstressed or weakly stressed syllables separate the main stresses. (8e) I want the vase broken cannot cause a phonological problem, because it involves a definite NP just like (9)/(17). (10a), however, involves an indefinite NP. Comparing it with (10b) I want a vase broken into small pieces one could argue that this pair reflects the same situation as (17) and (18). This, however, is only true under an analysis like the one given in (17), i.e., with a vase being assigned the V-role THEME by want. Want, however, also allows for the assignment of a V-role to the entire small clause. In this case, the truth conditions may well change. The object of want is then not some individual, but the situation of a breaking of a vase. ${ }^{13}$ Presumably, the appropriate phrase structure will look as follows.

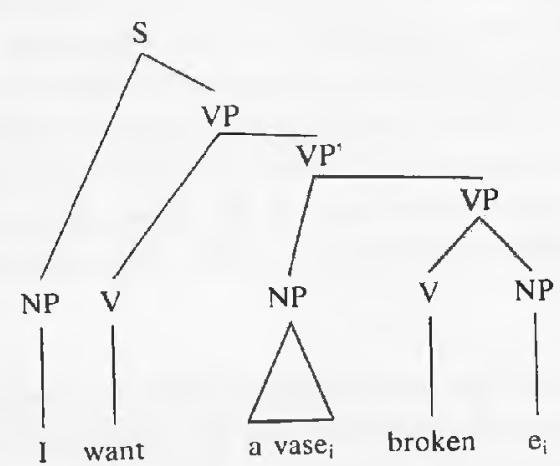

In (20) the syntactic object of want is VP'. The externalized NP receives Case from want under the standard assumption that a transitive verb can govern the specifier of a complement. In (20), I assume, [Spec,VP'] lacks a V-role, while the verb broken fails to assign Case to its object-NP. The structure fulfils Burzio's generalization. The object-NP, thus, undergoes NP-raising. The interesting thing is that this particular construction can have a prosodic structure not forcing contrastive stress on vase which still renders it fully acceptable.
(21)

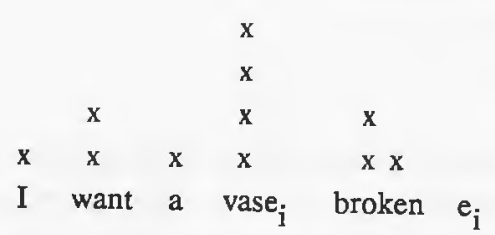

It should be clear that the syntactic structure must be responsible for distinguishing the euphonic grid in (21) from the cacaphonic grid in comparable examples with a vase being the direct object of want and broken being the head of a predicative AP.

The argumentation presented above, of course, leads to further questions as one tries to enlarge the data base. One could, for example, still not be convinced that the ill-formedness of $(6) /(18)$ derives from the fact that stress retraction cannot involve segments which are part of constituents which express new information. Mass-nouns can serve as contrastive cases. Notice that sentences such as They gove me vases broken are hardly better than $(6) /(18)$. Thus, if the reason for the ill-formedness is given by the bare $\mathrm{N}$-form alone, mass-terms should not fare any better. As the examples in (22) show, they do however.

(22)a. In Japan one drinks Sake warm

b. In Japan one eats fish raw

c. John drank Sake warm

d. John ate fish raw

The reason is to be sought in the fact that mass-terms do not automatically constitute new information. Thus, all the examples in (22) may well have the predicative AP-head stressed while the mass-noun retains relatively weaker stress.

Let me finally turn to Accusativus cum Infinitivo (ACI) constructions ('bare infinitives'). They share an important similarity with the want-construction represented in (20) above. De Geest (1972) was one of the first to observe that in these constructions the accusative-NP is only apparently semantically transparent for the governing verb. In his example from Dutch 
(23) I zie geloof overal ontbreken

I see faith everywhere lack

'I see faith lacking everywhere'

a violation of semantic selection would be committed, if things were otherwise. Similar arguments were independently brought forward in Gee (1975) and others, which show that the structure must be such that the matrix verb assigns a $\theta$-role to the SC and not to the SUBJECT of this SC. ${ }^{14}$ This state of affairs is partially predicted by the following syntactic representation.

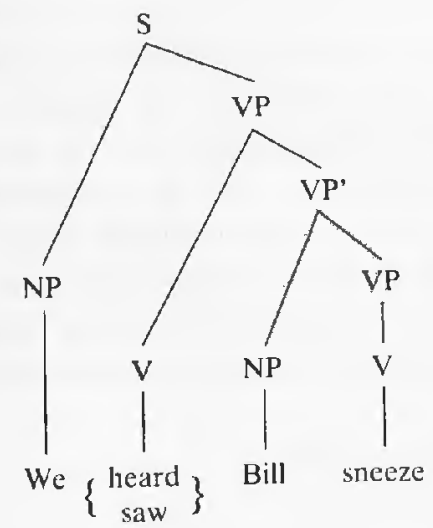

As in the want-construction (20), the object of perception must be the event of Bill's sneezing, not Bill as such. Does this have any consequences for the assignment of stress? I think, it does. The reason is that cyclic application of the NSR to (24) would naturally place the main stress onto sneeze. Once an indefinite NP is the SUBJECT of the ACI, however, this does not seem to be the case. As in (21), the most natural grid is one in which the predicate of the SC has a much weaker stress than the indefinite NP. An example whose syntactic structure is the same as the one in (24) is the following.
(25)

$\begin{array}{ccccc} & & & & \\ & & & x & \\ x & x & & x & x \\ \text { we } & x & x & x \\ \text { heard } & \text { a } & \text { a } & \text { child } & \text { sneeze }\end{array}$

Notice that the structure of (25) does not automatically lead to a reading according to which a child is used contrastively. (25) is a perfect 'out-of-the-blue' sentence. We do not need to invoke special rules to derive the difference between (21) and (25) on the one side and (24) on the other. The difference follows from the syntactic structure which distinguishes argument-SCs from adjunct-SCs such as (17) or (18). The only assumption we have to make is -- following Kiparsky (1966) -- that new the VP'-cycle this leads to additional beats the VP-cycle above, the NSR syllable. Thus, (25) can be derived already most prominent

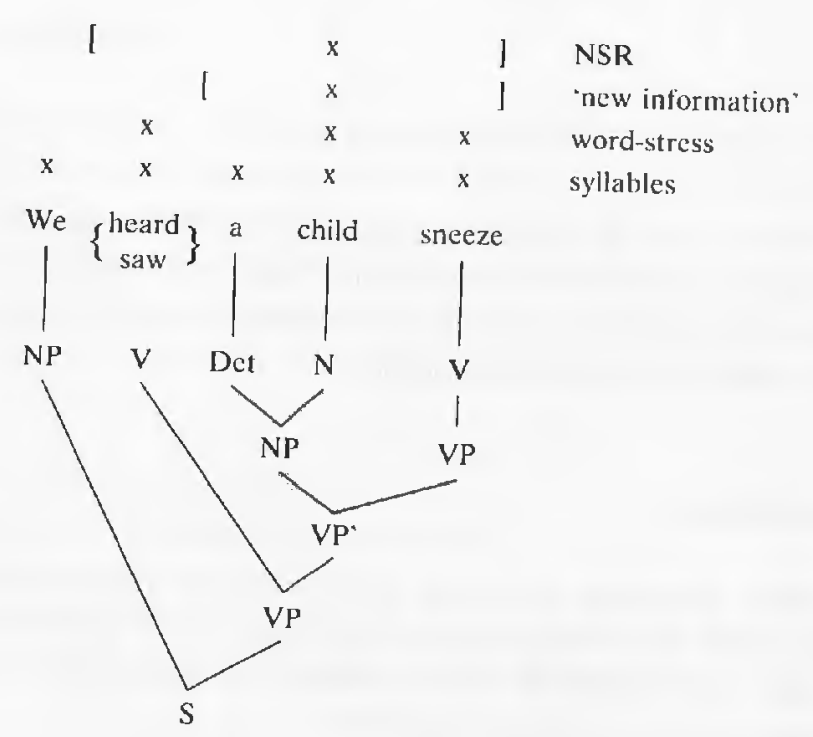


As a contrast, consider the ill-formed case (18). (18) involves an adjunct SC. Presumably the metrical grid is built in the following way.

(27)

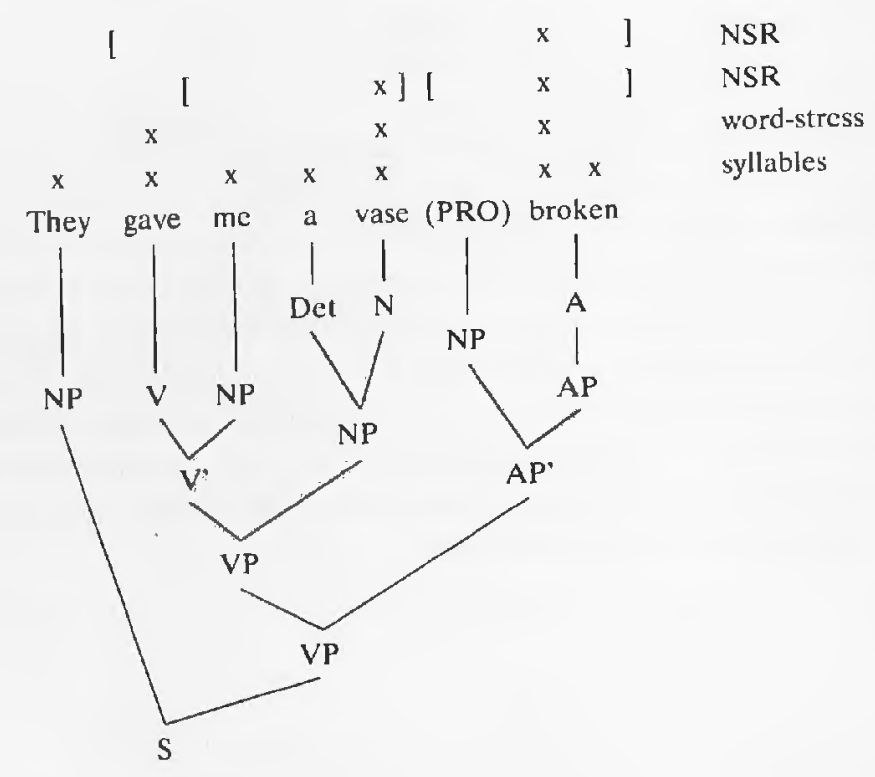

Notice that in (27) the lower application of the NSR coincides with the principle that new information must receive stress. The involvement of 'new information' will entail, however, that the RR cannot shift the offending stress to the left. Thus, a stress clash is unavoidable.

\section{Some Predictions}

If the above explanation is correct, certain manipulations of the ill-formed sentences should be able to improve their status. I will give examples below which show that contrastive stress, syntactic movement, coordination, and interpolation can indeed enhance acceptability.

\subsection{Contrastive Stress}

Imagine a discourse in which someone claims that he was given a broken vase by somebody. An interlocutor corrects him by saying

(28) (No), he gave you a JAR broken ${ }^{15}$

In this situation, jar is made extra prominent while broken being mentioned before counts as old information and can be destressed. This leads to a perfectly well-formed grid.

$\begin{array}{cllccc} & & & x & & \\ x & & & x & \\ x & x & x & x & & x \\ \text { he } & \text { gave } & \text { you } & \text { a } & \text { jar } & \text { (PRO) broken }\end{array}$

\subsection{Syntactic Movement}

We have argued that in a situation where the RR cannot dissolve a stress clash between two close segments $X$ and $Y$, the structure is ruled out on phonological grounds. When a syntactic transformation separates $X$ and $Y$, however, the structure should become acceptable. Let us consider an English example. "They gave us vases broken, and its equally bad German counterpart, "Sie gaben uns Vasen zerbrochen. Topicalization of vases/Vasen leads to well-formed results in both cases.

(30)a. Vases; they gave us $e_{i}$ [PRO broken]

b. Vasen ${ }_{i}$ gaben sie uns $e_{i}$ [PRO zerbrochen]

The reason for this is clear. In each case, the stressed topic-NP is separated from the stressed SC-predicate by a large enough number of weak(er) beats. 


\subsection{Coordination}

'Raddoppiamento Sintattico' leaves the stress pattern as it is assigned by the rules that govern word stress. It avoids the clash by quasi duplicating the onset of the second word. Thus, mèta tórta ('half cake') is changed by the rule of Raddoppiamento to mèta t:órta. ${ }^{16}$ Phonetically, this duplication may come out as a delayed release of the dental stop. The effect is a separation of the offending stresses. Something similar occurs in coordinative constructions. Coordinative constructions are not only constrained by the requirement of syntactic and semantic likeness of the conjuncts, they exhibit also a considerable amount of prosodic parallelism. This becomes most noticeable when the conjuncts are syntactically parallel, as in John danced and Mary sang, They worked in a palace but lived in a hut, or German Sie predigten Wasser und tranken Wein 'They preached water and drank wine'. At moderate speech rates, these examples are characterized by a pause before the conjunction and strictly parallel stress peaks in the conjuncts whereby the constituents in each conjunct in turn are separated by a small pause. If one wishes to couch this in rules inserting silent demibeats, Selkirk's rules in (14) could lead to the desired result. The examples above would get the following representation. ${ }^{17}$

(31)a. Jòn xxxx dánced $x x x x$ and Màry xxxx sáng xxxxx

b. They wòrked $x x$ in a pálace $x x x x$ but lived $x x$ in a hút $x x x x x$

c. Sie prèdigten $x x$ Wásser $x x x x$ und trànken $x x$ Wein $x x x x x$

(31b) and in particular (31c) could cause problems, because (14) does not insert enough silent demibeats in order to maximize the distance between the stress peaks in each conjunct. A rule would thus to be added to (14) which says:

(14') Maximize the distance between stress peaks above grid level three in syntactically parallel coordinate structures such that a minimum of $n$ weak beats or silent demibeats separates the stress peaks.

The value of $n$ may be dependent on the speech rate. As long as the rules in (14) do not suffice to produce the prosody of coordinative constructions, (14') could be invoked to insert pauses between the stress peaks. Whatever the ultimate technical execution of this idea is, it seems reasonable to provide for a separation of the otherwise clashing accents in examples like
(32)

\begin{tabular}{|c|c|c|c|c|c|c|c|c|c|c|}
\hline & & & & & $x$ & & & & & $x$ \\
\hline & & & $x$ & - & $--x$ & & & $x-\ldots$ & מבוב & $\cdots x$ \\
\hline & $x$ & & $\mathrm{x}$ & & $x$ & & & $x$ & & $x$ \\
\hline$x$ & $x$ & $x$ & $x x$ & $x x x$ & $x$ & $x x x$ & $x$ & $\begin{array}{ll}x & x\end{array}$ & $x x x$ & $x$ \\
\hline They & gave & us & vases & & clean & & but & glasses & & filthy \\
\hline
\end{tabular}

\subsection{Interpolation}

An explanation based on the eurhytmic scansion of a grid, of course, suggests that the intervention of unstressed material between the stress peaks should enhance acceptability. As the following examples show, also this expectation is borne out.

(33)a. * They gave me vàses broken

b. ? They gave me vàses mostly bróken

c. They gave me vàses most of the time broken

\section{Similar Accounts}

Let me finally mention that other linguists have argued that certain word order phenomena should be explained on the basis of clash avoidance in prosodic phonology. Bolinger (1972), for instance, observed contrasts such as the
following.

\section{(34)a. * He's a too odd man \\ b. He's a too unusual man \\ c. He's too odd a man \\ (35)a. * They are too odd men \\ b. ? They are men too odd \\ c. They are men who are too odd}

Too, being a particle which in $[X$ too $X]$ requires $X$ to bear stress, seems to be responsible for a stress clash between odd and man in (34a). The effect gets weaker in (34b), because the last two syllables of unusual separate the stress. It 
is worth considering cases like (34c) as the result of a syntactic reorganization triggered by the prosodic system to avoid accent clashes. Notice that (35a) forms a minimal pair with (36) below, which is perfectly acceptable.

\section{(36) They are two odd men}

The reason is presumably that two does not select odd as a focus as too does.

Similar examples were discussed by Woisetschlaeger (1980). He argues that 'local transformation' in the sense of Emonds' work such as the postposing of a degree phrase, conspire with the trend to achieve a pattern of alternating stresses. Even if the assumption about a derivational theory like this cannot be upheld, do I believe that word order alternation like those in (34) and (35) must be seen in close connection with the requirements of prosodic phonology.

\section{Conclusion}

On the basis of the evidence presented above it is reasonable to argue that examples such as (6) should not be ruled out on the basis of a violation of the PRO-theorem. Such an account faces at least problems with all the well-formed sentences having the same syntactic structure as (6), i.e. (9), (22a.-d.), (30a.,b.) and (32). Our account, which is based on recent results in metrical theory, can explain the ill-formedness of (6), while predicting the abovementioned examples and Chomsky's own examples in (8) to be well-formed. Recall that two things had to be stipulated in order to make the PRO-government proposal work for (8a) and (8c): Something is not a lexical governor, and S-deletion applies 'short', but not before 'long' APs. Both suggestions cannot be considered more than attempts at patching up with counterexamples. With a metrical explanation these problems become obsolete.

\section{Notes}

* This article is based on a proposal presented in the course of my doctoral thesis defense at the University of Konstanz 1982. Since then, a number of colleagues and friends have shaped my understanding of the issue considerably. Thanks to Guglielmo Cinque, Carlos Gussenhoven, Tilman Höhle, Aditi Lahiri, Wus van Lessen Kloeke, and Marga Reis. Of course, none of them should be held responsible for the analysis presented. I would also like to thank Grzegorz Dogil and Yves Fuchs for their help.

1. Notice that under (4) and (5), (2a) is only possible because $S$ is not considered a maximal projection. Under more recent development, e.g. Chomsky (1986) this raises a problem, because there $S=I N F L P$, a maximal projection.

2. While (8a-d) appear in the text, $(8 \mathrm{c})$ is given in footnote 12 of chapter 3 .

3. For lack of space, I will omit a thorough discussion of the stipulation that something does not count as a lexical governor. Let me, however, indicate that something broken may be far away from exhibiting a small clause. The reason is that in German, predicative APs do not show inflection, (e.g. by agreement with that in German, predicative APs do not show inflection, (e.g. by agreement with the subject). The equivalent of something broken, however, is very likely to syntactic analysis of this may be, the inflected form zerbrochen-es cannot be a predicative adjective.

4. The denial of syntactic influence reached a recent peak in Nespor and Vogel (1986). We will argue in this article that once the attention is drawn to more
(19) complex examples, this view is not called for.

\section{Selkirk (1984:314).}

6. The silent beats are in italics. Notice that one can possibly assume that Marcel in Marcel Proust is not an 'argument' and that it may be an adjunct (head) blocking an application of (14b). For convenience, I leave out the silent beats at the right end of the examples. The formal definition of the NSR given in Selkirk (1984:151) is:

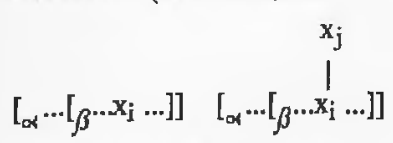

where $\alpha$ is a Phrase or S

Conditions:

(a) $x_{i}$ is first and last on its level

(b) $\mathrm{x}_{\mathrm{i}}$ is on metrical level three or higher

Notice, however, that nothing in the present discussion hinges on this particular version of the NSR. The intuitive idea is that in a syntactic phrase the stress of the right prominent syllable is amplified. 
7. $x$ marks a beat. Following the notation in Hayes (1984), the broken line indicates the level at which a stress class could occur. The silent beats inserted by (14) are underlined. Actually Selkirk's proposal is a bit different, but this does not affect my point here. See also Hayes (1984) for rules of metrical scansion.

8. Rendering the cardinality of beats by numbers:

\section{$\begin{array}{lll}3 & 2 & 4\end{array}$}

(i) Marcel Proust
$32 \quad 421$

(ii) UB library

9. A suggestion along these lines is made in Halle and Vergnaud (1987:271,fn29).

10. SUBJECT is a technical cover-term which among other things comprises the external argument of any kind of predicate. See Chomsky (1981:209ff).

11. See Hayes (1984) according to whom (17) would satisfy on the third grid level at least his Quadrisyllabic Rule and Phrasal Rule.

12. Both statements are in need of qualification, Selkirk (1984) proposes that new information (focus) is indicated by pitch accent. Pitch accent, however, requires at least a third-level prominence in order to escape destressing; see p.227. She also proposes that within a focus constituent pitch accent can be shifted along with Beat Movement.

13. My attention was drawn to this class of examples by Greg Carlson.

14. See also the arguments and analyses presented in Bayer (1982;1985).

15. Kiparsky observes a difference in German between (i) and (ii).

(i) Der Brief kam án The letter arrived

(ii) Ein Bríef kam an A letter arrived

16. Capitals should indicate contrastive stress. 17.See Nespor and Vogel (1979); when Raddoppiamento does not apply, the
stress of the first word must shift, as in meta tórta.

The main and secondary stresses are indicated by " - " and " - " 